\title{
师范院校化学专业英语教学中的课程思政建设
}

\author{
时凯歌 $1,{ }^{*}$, 杨光 ${ }^{2}$, 李永宇 1 \\ 1 郑州师范学院化学化工学院, 郑州 450044 \\ 2 郑州大学化学学院, 郑州 450001
}

\begin{abstract}
摘要: 师范院校探索化学专业英语的课程思政建设, 既丰富了化学专业英语课堂内容, 也有助于解答学生的思想困 惑。在分析师范院校化学专业英语课程特殊性及学生自身特点的基础上, 对该课程中的思政元素进行系统梳理, 探 索如何在听、说、读、写等教学环节中将专业知识与思政元素有机融合, 引导学生正确认识中西方文化差异, 培养 学生的辩证思维、爱国情操、文化自信和社会责任感, 以达到教书育人的目的。
\end{abstract}

关键词：化学专业英语；课程思政；师范院校；思政元素；立德树人

中图分类号: G64; O6

\section{Course Ideology and Politics Construction in Specialized English for Chemistry in Normal University}

\author{
Kaige Shi ${ }^{1, *}$, Guang Yang ${ }^{2}$, Yongyu Li ${ }^{1}$ \\ ${ }^{1}$ School of Chemistry and Chemical Engineering, Zhengzhou Normal University, Zhengzhou 450044, China. \\ ${ }^{2}$ College of Chemistry, Zhengzhou University, Zhengzhou 450001, China.
}

\begin{abstract}
Ideological and political education in the specialized English for chemistry in normal university should not only enrich teaching material in the classroom, but also help students solve ideological confusion. We present a systemic analysis of the ideological and political elements in this course based on particularity of the course and characteristics of the college students, explore the ways of organic integration of professional knowledge and ideological and political elements during the teaching process, and incorporate ideological and political education into listening, speaking, reading and writing sections. The aim of "course ideology and politics" is to guide students to correctly understand the differences between Chinese and Western cultures, cultivate students' dialectical thinking, patriotism, cultural confidence and sense of social responsibility, so as to achieve the purpose of teaching and educating college students.
\end{abstract}

Key Words: Specialized English for chemistry; Course ideology and politics; Normal university;

Ideological and political elements; Moral education and people cultivation

自习近平总书记在全国高校思想政治工作会议中提出“使各类课程与思想政治理论课同向而行” 的要求以来, 郑州师范学院积极探索专业教学与思政教育融合。专业教学解决的是如何培养人的问 题, 思政教育解决的是为谁培养人的问题, 这两个层次的问题有机统一于师范院校专业教学过程中。 课程思政建设要求教师在教学中挖掘专业课程的思政元素, 将学习专业知识与发挥课程的育人功能 
有机结合, 实现 “立德树人” 的目标。

目前世界科技书刊、文献资料和国际学术会议的工作语言大多数为英语, 掌握专业英语是加强 学科国际交流必备的语言工具。化学专业英语是一门面向化学和应用化学专业本科生开设的语言课 程, 一般为32-36学时。该课程内容包括本专业英语的语音、词汇、句式、语段、篇章等, 帮助学生 积累化学专业英语知识, 提高学生听、说、读、写、译等能力。基于学生专业发展的需要, 化学专 业英语教学备受关注。

习近平总书记提出 “思政建设融入高校课堂” 理念以来, 相关的有机化学、无机化学、分析化 学、物理化学和高分子化学的思政教育均有报道 ${ }^{[1-10]}$ 。针对有机化学教学过程中因重视知识传授而 忽略思政教育的问题, 刘志莲等 ${ }^{[8]}$ 提出, 授课时将 “培养创新精神、文化认同、职业素养和社会责任 感” 等思政元素和知识点深度融合, 让有机化学课程更有人情味, 实现高等教育教书育人的目的。 马亚鲁等 ${ }^{[7]}$ 注重 “无机化学与化学分析” 课程建设中的价值引领功能, 详细介绍如何将思政元素与 课程内容相结合, 在课堂讲授过程中力求培养学生的法制意识、家国情怀。段云青等 ${ }^{[9]}$ 在化学教学 实践中, 将量变与质变、对立与统一、普遍性与特殊性、现象与本质等唯物辩证法思想渗入课堂教 学中, 不仅帮助学生深刻理解学科知识, 还可以培养其辩证思维、科学探索精神和正确的世界观。 但是关于 “化学专业英语” 的思政建设目前为止尚未有相关报道。语言是文化和意识形态的载体, 也是其传播媒介, 学习一种语言必然要了解该语种承载的文化与意识形态。化学专业英语采用全英 教材, 课堂教学必然涉及英语所承载的西方文化和意识形态, 因此研究该学科的课程思政建设十分 必要。本文主要探讨如何在师范院校化学专业英语教学中开展思政建设。

\section{1 师范院校加强化学专业英语课程思政建设的必要性}

\section{1 是实现师范院校特定培养目标的必然要求}

师范院校的目标是培养面向未来的、德才兼备的教师。师范院校教学的特殊性在于: 今天的学 生就是未来的教师, 今天课堂上教师的教学行为和价值观, 将在若干年后影响这些学生未来的教育 行为和价值观, 进而影响更多学生的价值观。由于专业英语的课程特点, 若引导不当, 既无法实现 培养合格化学教师的目标, 产生的负面影响也会更加深远。过去的化学英语专业课程教学, 片面强 调专业知识的学习, 忽视育人导向, 欠缺对西方文化的辩证分析和对中国元素的凸显与阐释, 不利 于实现培养合格化学教师的目标。授课教师作为课堂教学的组织者和知识的传授者, 应该充分认识 师范院校中思政教育的重要性, 将思政元素融入课堂教学, 为师范生做好 “师” 范; 同时也有义务 帮助学生增强文化自信, 提高用英语讲好中国故事和阐释好中国特色的能力。加强师范院校化学专 业英语课程思政建设, 是一个影响未来教育发展的举措, 功在当代, 利在千秋。

\section{2 是化学专业英语课程健康发展的需要}

高等院校开展化学专业英语教学的目的在于培养既有学科专业知识, 又能够熟练运用英语进行 国际交流、技术创新的复合型人才。化学专业英语以英语为载体讲授无机化学、有机化学、分析化 学、物理化学等化学领域常用的专业术语与知识, 使学生掌握一定量实用的化学专业词汇, 逐步培 养学生的专业英语文献阅读和翻译能力, 开阔学生专业视野, 为学生毕业论文设计和继续深造提供 更多的选择方向。

语言是人类思维和交流的工具, 是文化的载体, 其本身也是文化的重要组成部分, 所以学习一 种语言就是在学习语言背后的文化。化学专业英语课程的内容和语言载体是英语, 在教学过程中, 除西方科学技术知识外, 也必然会涉及到一部分西方文化与价值观。大学生正处于世界观、人生观 和价值观形成的重要时期, 如果不注意引导, 就有可能使得部分学生在潜意识中形成对西方文化和 价值观的盲目认同。比如: 学习当中接触到的定律、原理、反应等等, 绝大多数都是西方学者发现 的, 并以他们的人名命名, 致使一部分学生对西方的科技成就与发展产生盲目的崇拜, 对我们国家 的科技赶超西方缺乏信心。在化学专业英语课堂上, 教师授课时不仅要讲授知识, 还需要培养学生 
对不同文化和价值体系的辩证思维能力, 引导学生对专业英语课程中的西方文化因素作出正确的价 值判断。因此加强思政建设是促进化学专业英语课程健康发展的必然要求。

\section{2 化学专业英语课程思政建设的探索}

\section{1 梳理章节知识中的思政元素, 把握思政教育和专业学习的融合点}

化学专业英语涵盖知识面广, 涉及到有机化学、无机化学、分析化学、物理化学、高分子材料、 科技论文写作等九个章节的内容。我们在教学实践中依据教学大纲、教学内容, 认真分析发掘每个 章节知识点中的 “思政元素”, 实现思政教育与化学专业知识的有机融合。如表1中, 在讲解易燃易 爆(flammable and explosion)专业词汇时, 可通过分析 2020 年 8 月 4 日黎巴嫩贝鲁特港硝酸铵仓库发生 的巨大爆炸事件 [11], 培养学生良好的科学行为习惯和安全责任意识; 在讲解有机化合物合成环节 (organic synthesis route)和聚烯烃的应用 (polyethylene application)时渗透绿色化学理念 ${ }^{[12]}$, 培养 “绿 水青山就是金山银山” 的环保和节能意识; 在科技论文写作(how to write scientific paper)章节, 通过 国内高校部分博士硕士因涉及学术不端行为(academic misconduct)而被撤销学位的案例, 对学生进行 学术诚信教育, 增强大学生自身诚信意识和法律修养 ${ }^{[13]}$ 。

\section{2 客观展示中西方化学研究现状, 引导学生正确认识西方文化的影响}

自近代以来, 西方主导了世界科技和经济社会发展。比如, 化学元素周期表中, 英国发现 23 个 元素, 瑞典和德国均为 19 个, 美国和法国各占 17 个, 中国为零。每年备受瞩目的诺贝尔奖项也大多 花落西方国家。面对这些数据, 教师在客观讲述西方学术界对化学发展贡献的同时, 还应向学生全 面介绍中国化学研究现状。近年来中国学者在化学研究领域经历了从模仿到并驾齐驱再到超越的过 程, 在一些细分领域已经走在世界的前列。每年全世界瞩目的美国化学会(American Chemical Society (ACS) meeting)中, 很多中国学者作为演讲者, 向全世界展现最前沿的化学科研成果。在化学专业英 语课堂上, 教师客观呈现西方的化学研究历史和现状以及中国化学领域取得的成就, 可以避免学生 对西方科技发展的盲目崇拜, 培养学生道路自信、理论自信、制度自信和文化自信。鉴于很多高校 教师具有国外学习和交流经历, 他们可以以自己的亲身经历作为课程思政建设的切入点, 用辩证唯 物主义和历史唯物主义的观点正确认识西方文化的影响, 为学生客观解读西方社会和科技发展现状。

\section{3 开辟单独章节讲解中国化学发展史, 彰显中国对化学发展的贡献}

著名化学家傅鹰说: “化学给人知识, 化学史给人以智慧。” 依据化学专业英语的特点, 我们在 本课程教学中开辟了化学发展史章节。中国古代化学成就辉煌, 五千年的文明史也是一部化学发展 史。中国古代的发酵技术、金属冶炼技术等为人类探索化学领域积累了丰富的实践经验, 造纸、火 药等制造工艺直接改变了人类文明的发展进程。公元前 100 年, 中国开始造纸, 公元 105 年东汉蔡伦 改进造纸术, 生产出了较为成熟的麻纸。造纸术经过丝绸之路传播到世界, 最终推动了欧洲的文艺 复兴。近代以后, 中国化学发展整体落后于西方, 但是仍然有很多学者取得了一定成就。例如民国 时期的侯德榜先生经过多年探索突破氨碱法制备碱, 并在 20 世纪 20 年代主持建成亚洲第一座纯碱厂, 成为我国重化学工业的开拓者。其生产的 “红三角” 牌纯碱曾在美国费城万国博览会上荣获金质奖 章。候先生的爱国情怀更是令人称道, 他曾经说过 “我自愿放弃美国舒适的生活, 立即返回祖国, 用自己的知识报效祖国”。新中国成立以来, 中国学者的研究成果日益受到国际关注。1965年第一次 人工合成牛胰岛素, 标志着中国科学家在蛋白质和多肽合成化学领域已经处于世界领先地位 ${ }^{[18]}$ 。 2015年屠呦呦凭借开创性地从中草药中分离出有效诊疗㾏疾的青蒿素, 获得诺贝尔生理学或医学奖, 标志着中国在医学领域获得重大突破。中国化学发展史为化学专业英语的课程思政建设提供了丰富 的教学资源, 也是教师引导学生解读自身文化优势、认同中华文化的重要途径。单独章节讲授中国 化学发展史能够帮助学生拓展知识、提高学科素养, 还可以培养学生的思辨精神、社会责任感、家 国情怀, 实现教书育人和立德树人的统一。 
大学化学 Univ. Chem. 2021, 36 (3), 2012006 (4 of 8)

表1 化学专业英语教学中具有中国特色的思政元素汇总

\begin{tabular}{|c|c|c|c|}
\hline $\begin{array}{l}\text { 教材章节 } \\
\text { (Chapter) }\end{array}$ & $\begin{array}{c}\text { 知识理论 } \\
\text { (Theoretical knowledge) }\end{array}$ & $\begin{array}{c}\text { 思政素材 } \\
\text { (Study materials of ideological and political } \\
\text { education) }\end{array}$ & $\begin{array}{c}\text { 思政目标 } \\
\text { (Objectives of ideological and political } \\
\text { education) }\end{array}$ \\
\hline $\begin{array}{l}\text { 绪论 } \\
\text { (Introduction) }\end{array}$ & $\begin{array}{l}\text { 化学发展史 } \\
\text { (History of chemistry) }\end{array}$ & $\begin{array}{l}\text { 火药的发明 } \\
\text { (The invention of gunpowder) } \\
\text { 侯德榜氨碱法制备碱技术 } \\
\text { (Hou's alkali method) }\end{array}$ & $\begin{array}{l}\text { 培养民族自豪感和辩证思维能力 } \\
\text { (Cultivate national pride and dialectical } \\
\text { thinking skills) }\end{array}$ \\
\hline $\begin{array}{l}\text { 无机化学 } \\
\text { (Inorganic chemistry) }\end{array}$ & $\begin{array}{l}\text { 砷 } \\
\text { (Arsenic) }\end{array}$ & $\begin{array}{l}\text { 张亭栋教授和陈竺院士用 “砒霜” 治疗 } \\
\text { 白血病 } \\
\text { (Dr. Tingdong Zhang and Academician Zhu } \\
\text { Chen use the arsenic in the treatment of } \\
\text { Leukemia) }\end{array}$ & $\begin{array}{l}\text { 传承优秀传统文化和培养文化自信 } \\
\text { (Inherit the excellent traditional culture and } \\
\text { cultivate cultural confidence) }\end{array}$ \\
\hline & $\begin{array}{l}\text { 稀土元素 } \\
\text { (Rare element) }\end{array}$ & $\begin{array}{l}\text { “稀土之父” 徐光宪院士的生平事迹[14] } \\
\text { (Life story of Academician Guangxian Xu, } \\
\text { who was known as “the Father of Chinese } \\
\text { Rare Earths Chemistry”) }\end{array}$ & $\begin{array}{l}\text { 培养“爱国、敬业”的社会主义核心价 } \\
\text { 值观 } \\
\text { (Cultivate the socialist core values of } \\
\text { “patriotism and dedication”) }\end{array}$ \\
\hline & $\begin{array}{l}\text { 卤素化合物 } \\
\text { (Halogen compounds) }\end{array}$ & $\begin{array}{l}\text { 如何使用含氯消毒液抗击新冠病毒 } \\
\text { (How to use halogen-containing disinfectant } \\
\text { to fight coronavirus) }\end{array}$ & $\begin{array}{l}\text { 学以致用, 开展劳动教育 } \\
\text { (Apply what you have learned and carry out } \\
\text { labor education) }\end{array}$ \\
\hline & $\begin{array}{l}\text { 易燃易炸 } \\
\text { (Flammable and explosion) }\end{array}$ & $\begin{array}{l}\text { 黎巴嫩爆炸事件 }[11,15] \\
\text { (Beirut explosion case) }\end{array}$ & $\begin{array}{l}\text { 培养安全意识 } \\
\text { (Cultivate safety awareness) }\end{array}$ \\
\hline \multirow[t]{4}{*}{$\begin{array}{l}\text { 有机化学 } \\
\text { (Organic chemistry) }\end{array}$} & $\begin{array}{l}\text { 有机官能团的命名 } \\
\text { (Naming organic functional } \\
\text { groups: amino, benzene) }\end{array}$ & $\begin{array}{l}\text { 电影《我不是药神》中的伊马替尼 } \\
\text { (imatinib)抗癌药 }{ }^{16]} \\
\text { (Imatinib was used as an effective anti- } \\
\text { cancer drug in the movie "Dying to } \\
\text { Survive") }\end{array}$ & $\begin{array}{l}\text { 关注民生, 培养家国情怀 } \\
\text { (Pay attention to people's livelihood issue, } \\
\text { and cultivate awareness of “family-country") }\end{array}$ \\
\hline & $\begin{array}{l}\text { 乙醇、甲醇的命名 } \\
\text { (Nomenclature of ethanol, } \\
\text { methanol) }\end{array}$ & $\begin{array}{l}\text { 商家以工业酒精或甲醇勾兑白酒事件 } \\
\text { (The cases of merchants blend liquor with } \\
\text { industrial alcohol or methanol) }\end{array}$ & $\begin{array}{l}\text { 树立法制意识, 提高社会责任感 } \\
\text { (Foster legal consciousness and develop a } \\
\text { sense of social responsibility) }\end{array}$ \\
\hline & $\begin{array}{l}\text { 二甲苯、四氯化钛的命名 } \\
\text { (Nomenclature of } \\
\text { dimethylbenzene, } \\
\text { Titanium tetrachloride) }\end{array}$ & $\begin{array}{l}\text { 阅兵式战机在蓝天画出一道道绚丽的 } \\
\text { “彩烟” 背后的化学故事 } \\
\text { (The military parade fighter draws the } \\
\text { chemistry story behind the brilliant “color } \\
\text { smoke” in the blue sky) }\end{array}$ & $\begin{array}{l}\text { 培养创新精神和环保意识 } \\
\text { (Initiative environmental awareness) }\end{array}$ \\
\hline & $\begin{array}{l}\text { 青蒿素 } \\
\text { (Artemisinin) }\end{array}$ & $\begin{array}{l}\text { 屠呦呦成功提取青蒿素, 获得诺贝尔生 } \\
\text { 理学或医学奖 } \\
\text { (Youyou Tu successfully extracted } \\
\text { artemisinin and won the Nobel Prize in } \\
\text { physiology or medicine) }\end{array}$ & $\begin{array}{l}\text { 传承优秀传统文化、增强文化自信 } \\
\text { (Inherit excellent traditional culture, enhance } \\
\text { cultural confidence) }\end{array}$ \\
\hline
\end{tabular}


(续表1)

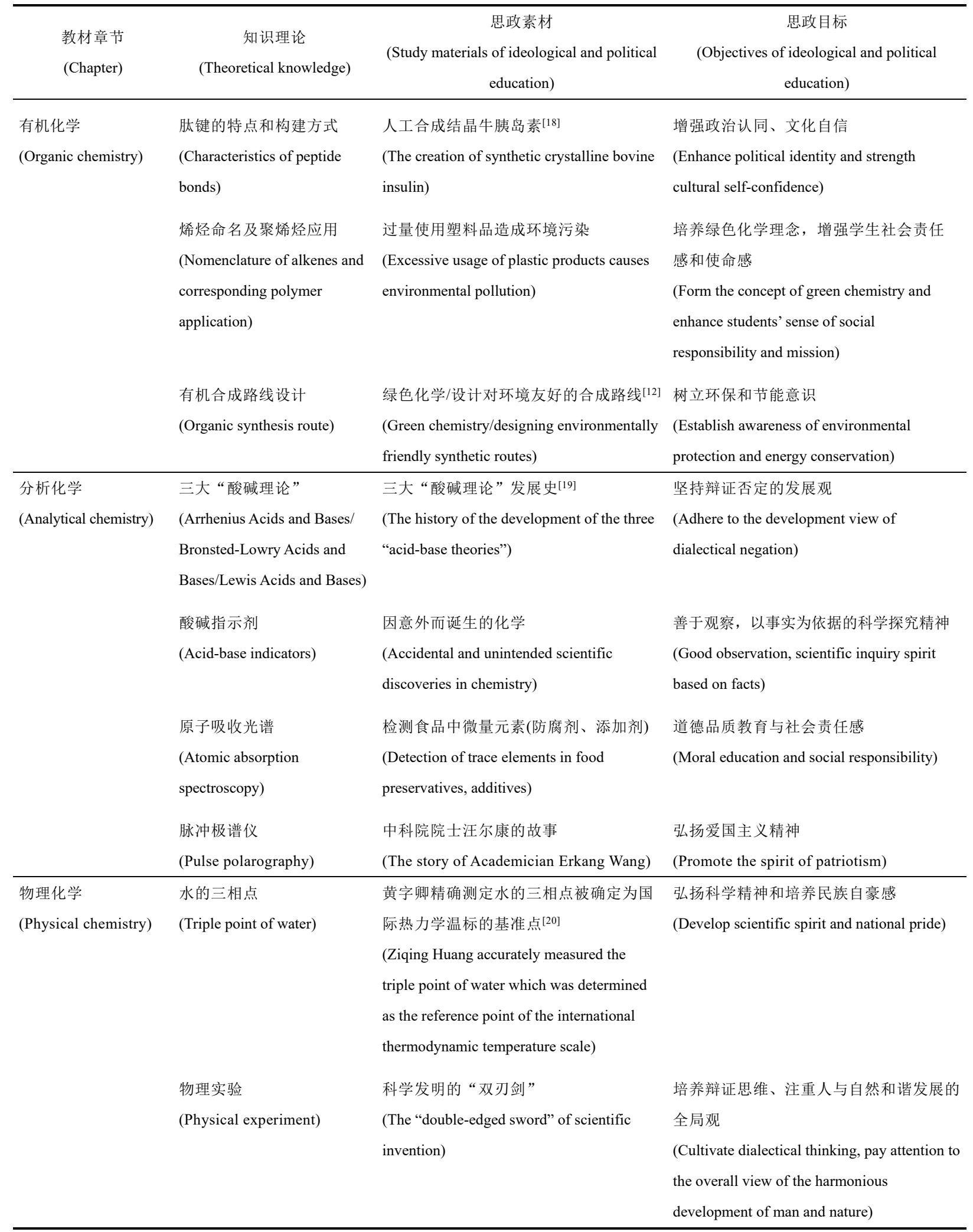


大学 化 学 Univ. Chem. 2021, 36(3), 2012006 (6 of 8)

(续表1)

\begin{tabular}{|c|c|c|c|}
\hline $\begin{array}{l}\text { 教材章节 } \\
\text { (Chapter) }\end{array}$ & $\begin{array}{c}\text { 知识理论 } \\
\text { (Theoretical knowledge) }\end{array}$ & $\begin{array}{c}\text { 思政素材 } \\
\text { (Study materials of ideological and political } \\
\text { education) }\end{array}$ & $\begin{array}{c}\text { 思政目标 } \\
\text { (Objectives of ideological and political } \\
\text { education) }\end{array}$ \\
\hline $\begin{array}{l}\text { 物理化学 } \\
\text { (Physical chemistry) }\end{array}$ & $\begin{array}{l}\text { 物理学科是材料、能源、环 } \\
\text { 境科学等热点领域的基石 } \\
\text { (Physics is the cornerstone of } \\
\text { hot fields in materials, energy } \\
\text { and environmental science) }\end{array}$ & $\begin{array}{l}\text { 不同学科知识的交叉 } \\
\text { (The intersection of knowledge in different } \\
\text { disciplines) }\end{array}$ & $\begin{array}{l}\text { 培养学生创新意识, 树立全局观念 } \\
\text { (Cultivate students' senses of Innovation, } \\
\text { establish the overall concept) }\end{array}$ \\
\hline $\begin{array}{l}\text { 新材料 } \\
\text { (New materials) }\end{array}$ & $\begin{array}{l}\text { 新材料的研发和应用 } \\
\text { (The development and } \\
\text { application of new materials) }\end{array}$ & $\begin{array}{l}\text { 陈忠伟院士等 }{ }^{[21]} \text { 在Nano Energy报道可构 } \\
\text { 建锂-硫电池的新材料 } \\
\text { (Academician Zhongwei Chen and others } \\
\text { reported a new material that can be used in } \\
\text { lithium-sulfur batteries in Nano Energy Li-S } \\
\text { batteries) }\end{array}$ & $\begin{array}{l}\text { 开展中国特色社会主义理论教育和中国 } \\
\text { 梦教育 } \\
\text { (Carry out socialist theory education with } \\
\text { Chinese characteristics and Chinese dream } \\
\text { education) }\end{array}$ \\
\hline $\begin{array}{l}\text { 英文科技论文写作 } \\
\text { (How to write scientific } \\
\text { paper in English) }\end{array}$ & $\begin{array}{l}\text { 学术不端 } \\
\text { (Academic misconduct) }\end{array}$ & $\begin{array}{l}\text { 再生心肌的干细胞丑闻[22] } \\
\text { (Stem cell scandal for myocardial } \\
\text { regeneration) }\end{array}$ & $\begin{array}{l}\text { 开展诚信教育 } \\
\text { (Honesty education) }\end{array}$ \\
\hline $\begin{array}{l}\text { 语法讲解时 } \\
\text { (Professional English } \\
\text { grammar explanation) }\end{array}$ & $\begin{array}{l}\text { 语言结构的特点 } \\
\text { (Characteristics of language } \\
\text { structure) }\end{array}$ & $\begin{array}{l}\text { 《党的十九大报告》双语全文(科学研 } \\
\text { 究、教育就业方面) } \\
\text { (The report of the 19th CPC National } \\
\text { Congress, related with scientific research, } \\
\text { education and employment) }\end{array}$ & $\begin{array}{l}\text { 推动习近平新时代中国特色社会主义思 } \\
\text { 想进课堂 } \\
\text { (Promote Xi Jinping's new era of socialism } \\
\text { with Chinese characteristics into the } \\
\text { classroom) }\end{array}$ \\
\hline
\end{tabular}

\section{4 依据课程思政建设要求, 创新 “听说读写” 的形式和内容}

“听、说、读、写” 是语言类课程教学的四项基本环节。依据课程思政建设的要求, 化学专业 英语课程教学既要保持传统特色和学科优势, 又要关注科技前沿, 不断创新教学的内容和形式。授 课教师可以建立具有思政特色的化学专业英语案例库, 从专业学科建设、科技前言、社会热点和知 识传授等方面传递正能量, 引导学生树立正确三观。

一是 “听(Listening)”。互联网对社会生活的全面渗透为化学专业英语听力教学提供了丰富的优 质网络资源, 可在听力训练环节引入《学习强国》中的 “对话科学家” 的系列视频。例如2014年诺 贝尔奖获得者爱德华. 莫索尔在采访视频中提出 “The prizes do not reflect the current situation of China” (是否获得诺奖并不能反映当前中国的科技水平)。他同时强调 “China is developing very fast in sciences and also in medical sciences, but of course the rewards of this will not come next year, and that one may not even come during next five or ten years, it will take a long time. I think what's important is that the focus shouldn't really be on getting as many Nobel Prizes as possible. I think the importance is to invest into science, and then see how that can be used to do some important challenges in society, and then the Nobel Prizes will come as a reward ${ }^{[23]}$.” (译文: 中国在科学领域和医学领域的发展非常迅速, 但是进步带来的回报并 不能立即到来, 而且未来五到十年甚至看不到, 这需要很长时间。重要的是, 不应该把重点放在诺 贝尔奖上, 而是加大科学投入, 然后看如何利用它为人类解决一些重要的问题, 然后获得诺贝尔奖 就是自然而然的事情)。通过这一段听力训练, 可以让学生深刻认识到, 在面对诺贝尔奖项的时候, 关注的重点在于推动科学的发展, 利用科学更好的为人类社会服务, 这种科学精神的传承将推动年 
轻一代崇尚科学, 引领中国重新回到世界科技的制高点。

二是 “说(Speaking)”。现代教育理念主张教师和学生共同创造课堂, 专业英语中的口语训练更 需要学生在教师指导下大胆参与并阐述自己的观点。比如学习元素 $\mathrm{T} 1$ 的时候, 为激发学生的兴趣, 教师在 “智慧树” 学习软件上提前上传 《Descriptive Inorganic Chemistry》教材中的相关段落 “ thallium poisoning: two case histories” (铊中毒事件), 供学生提前阅读 ${ }^{[24]}$ 。学生在课堂上介绍 $\mathrm{Tl}$ 元素的物理和 化学性质的英语专业术语时, 巧妙引出 “女大学生铊中毒事件”, 同时还使用经典名言 “the envious man often makes trouble for himself, which is his own enemy”, 倡导同学之间应该共同努力, 团结互 助, 一起迈向更好的明天。在教师指导下开展类似的口语训练, 一方面促进学生掌握新的英语单词, 养成清晰、流畅、达意的口语表达习惯, 另一方面将思政元素有机融入教学环节。

三是 “读(Reading)”。在教师指导下广泛阅读, 能够帮助学生深化对词汇的理解运用, 同时为写 作奠定基础。在阅读训练时, 可采用教科书中的经典素材, 也可选用 “学习强国” 中的《党的十九 大》和《习近平谈治国理政》(双语版)关于科学研究、教育、就业等方面的阅读材料, 还可选取 “科 技日报” (中国科技网英文版, Sci-Tech News, article)一些最新的和化学相关的报告。比如2020年4月 15日报道的 “Traditional Chinese medicine (TCM) plays big role in COVID-19 fight. The TCM practitioners hold that the key to combating an epidemic is to figure out its properties. They found that the novel coronavirus is most active in wet and cold environments with a temperature between $5{ }^{\circ} \mathrm{C}$ and $11{ }^{\circ} \mathrm{C}$ and a humidity of between $47 \%$ and $79 \%{ }^{[25]}$.” (译文: 中医学者认为, 抗击新冠病毒的关键是弄清其特性。研究发现, 该病毒在温度为 $5{ }^{\circ} \mathrm{C}-11{ }^{\circ} \mathrm{C}$ 和湿度为 $47 \%-79 \%$ 的环境下最为活跃)。此段阅读文本中, 既能让学生掌 握化学中常用词组、短语和化学专业英语句子, 又能让学生及时了解我国中医在防治新冠病毒中的 作用，培养学生的文化自信和民族自豪感。

四是 “写(Writing)”。写作主要是句子结构、语法和时态等方面的训练, 如长句(long sentences)、 被动句(passive sentences)、后置定语句(Postpositional attributives)、非限定动词(non-finite verb)、定语 从句(attributive clause)、一般过去时(past tense)和现代完成时 (present perfect tense)等, 目的在于提高 学生的英语书面表达能力, 能够正确书写科技论文。课程思政建设要求, 写作内容也应该及时关注 最新的社会热点话题, 实现英语语言文化、思维教育与思政教育有效对接, 训练学生用英语写好中 国的化学故事。

\section{5 精选翻译训练的文本, 凸显中国学者的贡献}

翻译训练是化学专业英语教学中的重要环节, 通过选择化学类经典英文素材进行翻译、点评和 对比, 可以拓展学生视野, 提高学生化学专业英语水平。近现代化学的主要成果源自西方, 故以往 翻译训练中的文本多选自西方著名化学家的经典著作。近年来随着中国在化学领域的迅速发展, 很 多科研专业团队的成果已经进入世界前列。在翻译训练环节, 我们可以打破以西方科技著作为主的 翻译模式, 采用中国学者在国际顶级期刊发表的与该课程紧密相关的最新化学科研论文进行翻译训 练。例如陈忠伟院士等人 ${ }^{[21]}$ 在2020年Nano Energy首次报道利用不饱和配位聚合物骨架作为多功能硫 储层, 构建高性能且耐用的锂-硫电池。选用该作品为翻译训练素材, 一方面有利于学生掌握课程的 重点专业词汇和翻译技巧, 提高学生专业英语水准, 另一方面帮助学生及时了解中国科研人员的研 究成果在国际的学术影响力和学术价值, 潜移默化地增强学生的文化自信心和民族自豪感。

\section{3 结语}

课程思政建设是专业教学与思政教育的有机统一, 是 “知识传授” 和 “价值引领” 的有机统一。 师范院校探索化学专业英语的课程思政建设, 既丰富了化学专业英语课堂内容, 同时有助于解答学 生的思想困惑, 树立科学的世界观、人生观和价值观, 增强学生的文化自信、爱国情怀和社会责任 感, 最终达到教书育人的目的。化学专业英语课程思政建设是一项庞大而系统的工程, 需要更多的 教育同行共同参与。 
参 考 文 献

[1] 张树永. 大学化学, 2019, 34 (11), 4 .

[2] 刘天府. 大学化学, 2020, 35 (8), 44.

[3] 张玉荣, 袁耀锋. 大学化学, 2021, 36 (3), 2007057.

[4] 余能芳, 张金兰, 任瑞, 蒋小妹, 曾艳, 刘盛华, 原弘. 大学化学, 2021, 36 (3), 2005040.

[5] 刘俊华, 谢云龙, 胡鸿雨. 广东化工, 2020, 13 (47), 212.

[6] 李芳清, 刘淑娟, 曹小红, 马建国. 东华理工大学学报(社会科学版), 2020, 39 (3), 276.

[7] 马亚鲁, 马骁飞, 田昀, 秦学, 高洪苓, 刘华姬, 鲁凡丽, 王晓东, 王兴尧, 李丹峰, 等. 大学化学, 2020, $35(8), 48$.

[8] 刘志莲, 崔玉, 刘思全, 杨小风, 王守锋. 大学化学, 2020, 35 (9), 31.

[9] 段云青, 段志青. 大学化学, 2020,35(12), 150.

[10] 魏明, 史红霞, 王梦婷, 安琼. 化学教育(中英文), 2020, 41 (18), 27.

[11] 徐飞, 谷巍, 吴啟南, 房方. 广东化工, 2020, 47 (23), 223.

[12] 叶美英, 大学化学, 2021, 36 (3), 2010031.

[13] 詹振运, 于瀚坤. 湖北经济学院学报(人文社会科学版), 2020, 17 (6), 89.

[14] 朱晶, 叶青, 黄艳红. 科技导报, 2014, 32 (10), 15 .

[15] 陶风，汤艺甜. 消防界(电子版), 2020,6 (17), 39.

[16] Talks aim to expand drug coverage by insurance. [2019-02-12]. http://www.chinadaily.com.cn/a/201902/12/WS5c61d76ca3106c65c34e8c55.html

[17] 黎润红, 张大庆. 中国科学院院刊, 2019, 34 (9), 1046.

[18] 新中国档案: 我国首次人工合成结晶牛胰岛素蛋白. [2009-09-27]. http://www.gov.cn/test/2009-09/27/content_1427654.htm

[19] Atkin, P.; Overton, T.; Rourke, J.; Weller, M.; Armstrong, F.; Hagerman, M. Shriver and Atkins' Inorganic Chemistry, 5th ed.; W.H. Freeman and Company: New York, USA, 2010; pp. 138-173.

[20] 计量史话. 中国计量, 2005, No. 3, 47 .

[21] Zhu, Y.-F.; Li, G.-R.; Luo, D.; Wan, H.; Feng, M.; Yuan, D.; Hu, W.; Li, Z.; Gao, R.; Zhang, Z.; et al. Nano Energy 2021, 79, 105393.

[22] Harvard and the Brigham call for more than 30 retractions of cardiac stem cell research. [2018-10-14]. https://www.statnews.com/2018/10/14/harvard-brigham-retractions-stem-cell/

[23] 对话科学家. [2020-02-25]. https://www.xuexi.cn/lgpage/detail/index.html?id=18142428609898355923

[24] Rayner-Canham, G.; Overton, T. Descriptive Inorganic Chemistry, 5th ed.; W. H. Freeman and Company: New York, USA, 2010; pp. 216-223.

[25] Traditional Chinese medicine plays big role in COVID-19 fight. [2020-10-09]. http://www.stdaily.com/English/China News/2020-10/09/content_1025900.shtml 